\title{
Tick trails: the role of online recreational trail reviews in identifying risk factors and behavioral recommendations associated with tick encounters in Indiana
}

\author{
Kristina R. Anderson ${ }^{1 *}$, Jordan Blekking ${ }^{2}$ and Oghenekaro Omodior ${ }^{1}$
}

\begin{abstract}
Background: Recreational trails abound across the United States and represent high risk areas for tick exposure. Although online reviews represent a rich source of user information, they have rarely been used in determining the risk of tick exposure during recreational trail use. Based on online user reviews and comments, the purpose of this study was to determine risk factors and behavioral recommendations associated with tick encounters (Tick Presence) on recreational trails in the state of Indiana, U.S.
\end{abstract}

Methods: We reviewed 26,016 user comments left on AllTrails.com for 697 Indiana trails. Reviews were evaluated to determine Tick Presence/Absence, the total number of Tick Presence Reviews per trail, and multiple trail and user behavioral characteristics. We used hot spot (Getis-Ord $\mathrm{Gi}^{*}$ ) analysis to test the hypothesis of whether there are clusters in the number of Tick Presence Reviews. Pearson chi-square tests of independence evaluated whether tick presence was associated with several trail characteristics. Finally, negative binomial regression evaluated the strength of the association between the number of Tick Presence Reviews and several trail characteristics.

Results: Tick Presence was recorded at 10\% $(n=65)$ of trails and occurred most frequently in May. Hot spot analysis revealed statistically significant clusters of Tick Presence Reviews on trails in the Southern Indiana State Region. Results of $x^{2}$ tests indicated significant associations between Tick Presence Reviews and (a) State Region and (b) Land Management Type; Mann-Whitney U tests detected significant differences in Tick Presence Reviews based on Trail Length and Elevation Gain. Subsequent results of a negative binomial regression model indicated that Southern Indiana State Region, Federal and Private Land Management Type, and Elevation Gain were factors significantly associated with Tick Presence Reviews. Content of user reviews indicated several behaviors employed to prevent tick encounters, particularly Repellent Application and Recreational Deterrence; 25\% included a behavior Recommendation to others.

Conclusions: Online, user-generated trail reviews have the potential to serve as rich data sources for identifying recreational trails, where 1) the risk of tick exposure is great, 2) more robust active tick and tick-borne pathogen surveillance may be warranted, and 3) tailored prevention interventions are needed.

Keywords: Tick exposure, Risk factor, Protective behavior, Recreation, User behavior

\footnotetext{
* Correspondence: anderskr@indiana.edu

'Department of Health \& Wellness Design, School of Public Health, Indiana University Bloomington, 1025 E. 7th Street, IN 47405 Bloomington, USA

Full list of author information is available at the end of the article
}

C C The Author(s). 2021 Open Access This article is licensed under a Creative Commons Attribution 4.0 International License, which permits use, sharing, adaptation, distribution and reproduction in any medium or format, as long as you give appropriate credit to the original author(s) and the source, provide a link to the Creative Commons licence, and indicate if changes were made. The images or other third party material in this article are included in the article's Creative Commons licence, unless indicated otherwise in a credit line to the material. If material is not included in the article's Creative Commons licence and your intended use is not permitted by statutory regulation or exceeds the permitted use, you will need to obtain permission directly from the copyright holder. To view a copy of this licence, visit http://creativecommons.org/licenses/by/4.0/ The Creative Commons Public Domain Dedication waiver (http://creativecommons.org/publicdomain/zero/1.0/) applies to the data made available in this article, unless otherwise stated in a credit line to the data. 


\section{Background}

Over the past fifteen years, reports of tick-borne diseases have grown across the United States (U.S.), with the decade from 2007 to 2017 representing a near-doubling in total reported tick-borne diseases [1, 2]. Ticks are prevalent across all 48 contiguous states, and the geographic range of tick distribution continue to expand [3, 4]. Among the various settings where exposure to zoonotic agents (tick, mosquitoes, fleas) occurs, spaces for public outdoor recreation are notable among visitors and personnel alike, and the risk associated with recreational tick encounters varies dramatically based on tick abundance as well as temporal and spatial factors [5-9].

In one survey of state parks across Oklahoma, researchers identified that the potential tick encounter rate varied from 32.1 ticks per hour at one park in May to less than one per hour at another park during the peak summer season [6]. The role of public recreational sites as sites of tick exposure can also vary by U.S. region. In Connecticut, where ticks are largely endemic, time spent in one's old yard, as opposed to public recreation sites, was significantly more predictive of individuals' tick detection [10]. Conversely, in a study of tick exposure among California residents, tick encounters occurred in natural areas of recreation more than $80 \%$ of the time, in contrast to peri-domestic settings $(\leq 15 \%)$ [11]. Still, few inquiries into recreational tick exposures have taken place in the U.S.'s Midwest region. Additionally, extant literature has identified limited characteristics associated with tick presence in recreational spaces, such as specific habitat attributes [12, 13]. For instance, whereas evidence indicates that a property's land management level influences its scope of tick surveillance and pathogen detection initiatives [14], the association between various management levels and tick presence is less well understood.

The body of literature examining behaviors associated with known or anticipated tick encounters at sites of outdoor recreation is also limited; one study conducted in Florida found that less than one-third of visitors acknowledged practicing tick protective behaviors, such as applying insect repellent, each time they visit a recreational site, despite the majority indicating high intention to engage in those behaviors [15]. Other research has evaluated the role of recreational deterrence, wherein an individual avoids outdoor recreation in a given location due to anticipated or known tick presence, although the rate at which individuals adopt this strategy ranges widely, from 7 to $59 \%$ [16-18].

Public outdoor recreation spaces also represent a particularly unique challenge from an epidemiological, public health perspective: Because users of these spaces often include nonresidents of the local area who may recreate in one area and travel prior to discovering a tick bite and/or seeking medical treatment due to tick-borne disease symptoms, discrepancies can occur in understanding local risks of vector-borne disease [19]. Additionally, even if the specific site of vector exposure is identified, the degree to which this knowledge is successfully communicated to the relevant, local public health agency is unknown [19]. Consequently, these challenges represent a need for innovative approaches to identifying and understanding tick encounters in areas of public outdoor recreation.

To better identify and understand recreational tick encounters, this study seeks to employ online user reviews of recreational trails in Indiana, U.S. to address three gaps in extant literature. Our first research objective seeks to use online user reviews to pinpoint locations of tick encounter (Tick Presence), as well as identify specific spatial and temporal patterns in Tick Presence. Leading scholars have denoted the need for this type of scholarship to improve the use of spatial epidemiologic data in understanding vector-borne diseases, particularly calling for identification of patterns at finer scales, i.e., more detailed than county-level [14, 20]. Second, given available data with each trail's online profile, we seek to identify trail characteristics, such as Land Management Type, that are associated with The Presence. Our final research objective seeks to understand behavioral responses associated with Tick Presence at public sites of outdoor recreation, a noteworthy contribution, as existing research has generally relied upon survey-based, self-reported practices, a strategy which depends on recall and often results in over-reporting of socially-desired behaviors [21]. Concomitantly, given that current determinations of Tick Presence generally occur through active surveillance processes, e.g. deployment of field-based teams to conduct in-situ drag sampling $[6,7,12]$ we also contribute a methodological advancement which is cheaper than population-based surveys and can be employed even with limited resources through analysis of online user reviews.

Our study findings and methodological innovation may have important implications for 1) developing tailored and targeted population-level public health interventions aimed at tick exposure risk reduction in Indiana, 2) identifying novel approaches in the collection of data for passive surveillance, not just for tick exposure risk, but for other vector-borne disease risks, and 3) initiating similar studies not only across every U.S. state, but internationally [22].

\section{Methods}

Data source and collection

AllTrails was employed as the online user review data content source due to its prominence within the recreational trail user community; as of October 2020, the 
website reported global trail use on more than 100,000 trails by greater than 20 million "explorers" [22]. AllTrails allows users to search for trails by state, city, park site, and average user rating, among other characteristics. Each individual trail page reports on several trail characteristics, such as elevation gain; lists user reviews; and provides a trail map. Users are encouraged to rate trails and leave reviews, which can include photos and/ or waypoints to demark a specific feature along the trail. Users may access limited information via free web access or pay a monthly subscription fee for premium access.

Every trail located in [1] the state of Indiana and [2] included in the AllTrails.com database as of October 31, 2020 was included in the study. This resulted in a review of 697 trails across Indiana. For each trail, additional data was recorded including longitude/latitude of the trailhead, Trail length (in miles), Elevation Gain (in feet), Route Type, and associated park/nature site/location, as indicated by AllTrails.com. The review date was also recorded as a proxy for exposure date, under the assumption that the review was posted promptly following the trail visit the same day, or very shortly thereafter. Based on spatial location denoted by longitude/latitude, trails were coded for presence in the north, central, and southern regions of the state according to County Surveyors Association of Indiana [23] designation, resulting in a State Region variable. Additionally, the Land Management Type (e.g. municipal, county, state, federal, private, and unknown) of each was recorded; this was derived from either the indicated park/nature site name (e.g. "Brown County State Park", indicating state ownership), or an internet search, if the ownership type was not initially apparent.

\section{Inclusion/exclusion criteria}

All reviews recorded during an approximately 3-season period from April 1-October 31st over a two-year period (2019 and 2020 seasons) were evaluated for a reference to "tick" or "ticks", excluding terms such as "stick" or "sticker" that are not relevant in meaning. These dates were selected because, April through October reflects the general period of most tick activity in the Midwestern US [24] as well as general recreational use of trails in Indiana [25].

\section{Data analysis}

After a search to identify reviews including the term "tick(s)", all tick-related reviews were recorded. The unit of analysis reflected each singular AllTrails user review, and one member of the research team initially evaluated each review for content broadly related to tick presence/ absence, tick description (e.g. size, count), protective behaviors, and tick-related recreational deterrence. These themes were based on a cursory review of tick-related reviews from 20 Indiana trails, a priori content area knowledge of the research team, as well as the example of Liu, Pennington-Gray [26] who adopted a similar methodology in their study of user bed bug perceptions on TripAdvisor.com. After completing this initial evaluation, the researchers met to discuss these initial findings, finalize codes and group them by theme; during this time the research team also collectively interpreted 19 reviews that had been flagged by the initial researcher who was uncertain whether those reviews reflected a general comment about ticks or an actual tick encounter. After this meeting, one researcher proceeded to reassess the reviews again in line with the revised codes and definitions.

The final themes included tick experience (Tick Presence, Tick Absence, and Tick General), tick protective behaviors (including three self-reported behaviors including Repellent Application, Protective Clothing, and Shower Post-Recreation as well as one reflecting Recommendation of protective behavior(s) to other users/ readers, as well as a theme related to Recreational Deterrence. A complete list and definition of each is provided in Table 1.

Beyond evaluation of user review narrative content, quantitative analysis also evaluated Tick Presence as a binary per trail, wherein if any review of that trail indicated Tick Presence, the value would be set at 1 (no reviews indicating tick presence at a given trail resulted in 0). A total number of reviews indicating tick presence per trail was also calculated as Tick Presence Reviews; additionally, the percentage of each's trail total reviews indicating tick presence was also calculated (i.e. Tick Presence Reviews \% of Total). Maps reflecting these total and relative counts of Tick Presence were created using Tableau 2020.2. Hot spot (Getis-Ord Gi*) analysis was conducted in ArcGIS Desktop 10.7 to identify significant spatial clusters of trails within Indiana. $\chi^{2}$ tests of association evaluated relationships between Tick Presence and several trail characteristic variables including State Region, Land Management Type, and Route Type; Mann-Whitney U tests were employed to evaluate differences in Trail Length and Elevation Gain based on Tick Presence, given that these variables did not reflect normal distributions.

We then utilized a negative binomial regression to evaluate the relationship between these variables and the outcome variable of Tick Presence Reviews, a value which reflected a count of all comments indicating Tick Presence at each trail. While Poisson models are frequently used to model count data, our data exhibited overdispersion (wherein conditional variances exceeded that of conditional means), thus calling for the use of the negative binomial model. Statistical analysis was conducted with IBM@ SPSS version 27.0 (https://www.ibm. com/products/spss-statistics). 
Table 1 Tick-Related User Review Themes ( $N=147)$

\begin{tabular}{|c|c|c|c|}
\hline Theme & Concept & Definition & $\mathrm{n}, \%$ \\
\hline \multicolumn{4}{|c|}{ Tick experience } \\
\hline & Tick presence & User explicitly indicates presence of tick(s) in review & $124(84.4 \%)$ \\
\hline & Tick absence & User explicitly indicates absence of tick(s) in review & $20(13.6 \%)$ \\
\hline & Tick general & $\begin{array}{l}\text { User makes a general comment about tick(s), but does not clearly } \\
\text { indicate tick encounter in review }\end{array}$ & $3(2.04 \%)$ \\
\hline \multicolumn{4}{|c|}{ Tick protective behavior } \\
\hline & Repellent application & Reference to having applied insect repellent prior to tick encounter & $14(9.52 \%)$ \\
\hline & Protective clothing & $\begin{array}{l}\text { Reference to having made intentional clothing choices } \\
\text { (e.g. long clothes, light-colored clothes, or treated clothes) prior to } \\
\text { tick encounter }\end{array}$ & $5(3.40 \%)$ \\
\hline & Shower post-recreation & Reference to having taken a shower post recreational activity & $2(1.36 \%)$ \\
\hline & Recommendation & $\begin{array}{l}\text { Review makes explicit recommendation to other users, which includes } \\
\text { one or more suggestions for how to prevent tick bites }\end{array}$ & $37(25.17 \%)$ \\
\hline \multicolumn{4}{|c|}{ Recreational deterrence } \\
\hline & Recreational deterrence & $\begin{array}{l}\text { Review suggests that the user disengaged from use of that trail in the } \\
\text { moment or plans to avoid the trail in the future due to the tick encounter }\end{array}$ & $11(7.48 \%)$ \\
\hline
\end{tabular}

\section{Results}

Over the two-year period, users recorded 26,016 trail reviews: 6729 in 2019 and 19,287 in 2020. Of these, 147 (0.57\%) reviews referenced ticks; 38 in 2019 and 109 in 2020. However, not all of these were indicative of a tick encounter. Of the 147 reviews referencing ticks, 124 indicated Tick Presence, 20 indicated Tick Absence and 3 indicated Tick General. Tick Presence was recorded at 65 Indiana trails (of 697 trails total), or $9.46 \%$ of trails.

A sample of those 65 trails, illustrating rank order of the top 10 trails by (a) tick-related reviews as a percentage of total reviews and (b) total number of tick-related reviews are outlined in Table 2. A full summary of the 65 trails is provided in Appendix A. Notably, most $(n=$ 43) of those trails indicated tick encounter by just one user review. The remaining 22 indicated tick presence by more than one user review; the maximum number of tick-related reviews of any trail was 13 (Two Lakes Loop Trail, Branchville, IN).

\section{Spatial and temporal tick encounter patterns}

Figure 1 illustrates all 697 trails across the Hoosier state, with and without Tick Presence, as well as total Tick Presence Reviews, as shown through graduated symbol size. Visually, the Southern Indiana region reflects higher rates of reported tick encounters, particularly near the Hoosier National Forest (adjacent to the Ohio River). Subsequent hot spot analysis further identified a collection of hot spot values in this area (Fig. 2). No cold spots were identified in the analysis.

In evaluating seasonality of tick encounters, the month in which most tick encounters (Tick Presence Reviews) were reported was May, with steady decline as the summer proceeded into the fall season, with October representing the month indicating the fewest reported tick encounters (Fig. 1). This pattern was generally reflected both in 2019 and 2020, as well as overall.

\section{Trail characteristic associations}

Analysis of trail characteristic associations (Table 3) indicated significant associations between Tick Presence and trails' State Region X2 $(2, N=697)=55.30$, $p<0.001$; notably, $77 \%(n=50)$ of trails indicating tick presence were located in the Southern portion of the state, whereas only $31 \%(n=198)$ of trails that did not indicate tick presence were located in this region. Significant associations were also identified between Tick Presence and Land Management Type $\mathrm{X}^{2}(5, N=697)=$ $61.15, p<0.001$. The plurality of trails reflected state land management (36\% overall, $n=251)$ although this varied by tick presence $(48 \%, n=31)$ and the lack thereof $(35 \%, n=220)$. Loop was the most frequent trail route type $(74 \%, n=516)$; however, no significant associations were identified based on Route Type and Tick Presence $\mathrm{X} 2(2, \mathrm{~N}=697)=2.11, p=0.348$. While the average Trail Length was 4.4 miles $(\mathrm{Mdn}=2.4)$, this metric was significantly higher on trails indicating Tick Presence $(M=6.2$, $M d n=4.4)$ than those that did not $(M=4.2, M d n=2.2)$ $(U=12,552, p<0.001)$. Similarly, the average Elevation Gain on trails was 320.2 miles $(\mathrm{Mdn}=124)$, with a significantly higher average gain on trails indicating Tick Presence $(\mathrm{M}=721.3, \mathrm{Mdn}=472)$ than those that did not $(\mathrm{M}=278.9, \mathrm{Mdn}=110)(U=9460, p<0.001)$.

\section{Negative binomial model results}

The negative binomial regression model identified several statistically significant associations between tick trail characteristics and Tick Presence Reviews (Table 4). 
Table 2 Tick Presence Reviews at Select Trails

\begin{tabular}{|c|c|c|c|c|c|c|c|c|}
\hline \multirow[t]{2}{*}{ No. } & \multirow[t]{2}{*}{ Trail } & \multicolumn{3}{|c|}{ Tick Presence Reviews } & \multicolumn{3}{|c|}{$\begin{array}{l}\text { All User } \\
\text { Reviews }\end{array}$} & \multirow{2}{*}{$\begin{array}{l}\text { Tick } \\
\text { Presence } \\
\text { Reviews } \\
\% \text { of } \\
\text { Total }\end{array}$} \\
\hline & & 2019 & 2020 & Total & 2019 & 2020 & Total & \\
\hline \multicolumn{9}{|c|}{ Top 10 Trails by Tick Presence as Percentage of Total } \\
\hline 1 & Rabbit Hash Trail & 1 & 3 & 4 & 1 & 4 & 5 & $80 \%$ \\
\hline 2 & Columbia Mine Preserve Loop & 0 & 4 & 4 & 1 & 10 & 11 & $36 \%$ \\
\hline 3 & German Ridge Lake Trail & 0 & 3 & 3 & 3 & 10 & 13 & $23 \%$ \\
\hline 4 & Birdseye Trail & 1 & 2 & 3 & 6 & 12 & 18 & $17 \%$ \\
\hline 4 & Trail 8 and Pine Bluff Shelter & 0 & 2 & 2 & 2 & 10 & 12 & $17 \%$ \\
\hline 4 & Thomas Ciurus Nature Preserve & 1 & 0 & 1 & 2 & 4 & 6 & $17 \%$ \\
\hline 7 & Violet and Louis Calli Nature Preserve & 0 & 3 & 3 & 3 & 18 & 21 & $14 \%$ \\
\hline 7 & Shaw Lake Loop Trail & 0 & 2 & 2 & 5 & 9 & 14 & $14 \%$ \\
\hline 7 & Ropchan Memorial Trail & 0 & 1 & 1 & 1 & 6 & 7 & $14 \%$ \\
\hline 8 & Two Lakes Loop Trail & 6 & 7 & 13 & 35 & 68 & 103 & $13 \%$ \\
\hline 8 & Turkey Roost Run Trail & 1 & 1 & 2 & 7 & 9 & 16 & $13 \%$ \\
\hline \multicolumn{9}{|c|}{ Top 10 Trails by Total Tick Presence } \\
\hline 1 & Two Lakes Loop Trail & 6 & 7 & 13 & 35 & 68 & 103 & $13 \%$ \\
\hline 2 & Adventure Hiking Trail & 1 & 5 & 6 & 25 & 85 & 110 & $5 \%$ \\
\hline 3 & $\begin{array}{l}\text { Laura Hare Nature Preserve Trail at } \\
\text { Downey Hill Full Loop }\end{array}$ & 1 & 4 & 5 & 27 & 104 & 131 & $4 \%$ \\
\hline 4 & Lake Monroe Peninsula Trail & 2 & 2 & 4 & 74 & 137 & 211 & $2 \%$ \\
\hline 4 & Patoka Lake Main Trail & 0 & 4 & 4 & 17 & 49 & 66 & $6 \%$ \\
\hline 4 & Shawnee and Lenape Trail Loop & 0 & 4 & 4 & 6 & 35 & 41 & $10 \%$ \\
\hline 4 & Columbia Mine Preserve Loop & 0 & 4 & 4 & 1 & 10 & 11 & $36 \%$ \\
\hline 4 & Rabbit Hash Trail & 1 & 3 & 4 & 1 & 4 & 5 & $80 \%$ \\
\hline 9 & Cowles Bog Trail & 1 & 2 & 3 & 114 & 305 & 419 & $1 \%$ \\
\hline 9 & Sycamore Loop Trail & 1 & 2 & 3 & 38 & 75 & 113 & $3 \%$ \\
\hline 9 & Tipsaw Lake Trail & 1 & 2 & 3 & 8 & 27 & 35 & $9 \%$ \\
\hline 9 & Allen's Creek & 1 & 2 & 3 & 3 & 29 & 32 & $9 \%$ \\
\hline 9 & Hickory Ridge Trail & 0 & 3 & 3 & 9 & 20 & 29 & $10 \%$ \\
\hline 9 & Cave River Valley Trail & 0 & 3 & 3 & 3 & 26 & 29 & $10 \%$ \\
\hline 9 & Violet and Louis Calli Nature Preserve & 0 & 3 & 3 & 3 & 18 & 21 & $14 \%$ \\
\hline 9 & Birdseye Trail & 1 & 2 & 3 & 6 & 12 & 18 & $17 \%$ \\
\hline 9 & German Ridge Lake Trail & 0 & 3 & 3 & 3 & 10 & 13 & $23 \%$ \\
\hline
\end{tabular}

Holding all other variables in the model constant and compared to trails located in the Northern State Region, trails located in the Southern State Region were significantly more associated with each unit increase in Tick Presence Reviews $(p<0.001)$. Additionally, trails reflecting Federal $(p<0.001)$ and Private Land Management Type $(p<0.047)$ were significantly more likely than trails of Municipal land management to be associated with each unit increase in Tick Presence Reviews, ceteris paribus. Finally, after holding all other model variables constant, Elevation Gain (in feet) was also found to be significantly associated with each unit increase in Tick Presence Reviews $(p=0.050)$.

\section{Protective behaviors}

Beyond general comments indicating whether the user encountered a tick(s) or not, one recurrent theme identified across several reviews reflected the use and recommendation of protective behaviors known to either repel ticks or prevent tick bites. Several users explicitly indicated that they had engaged in Repellent Application $(n=14 / 147,9.52 \%)$ during their recreational trail use; 


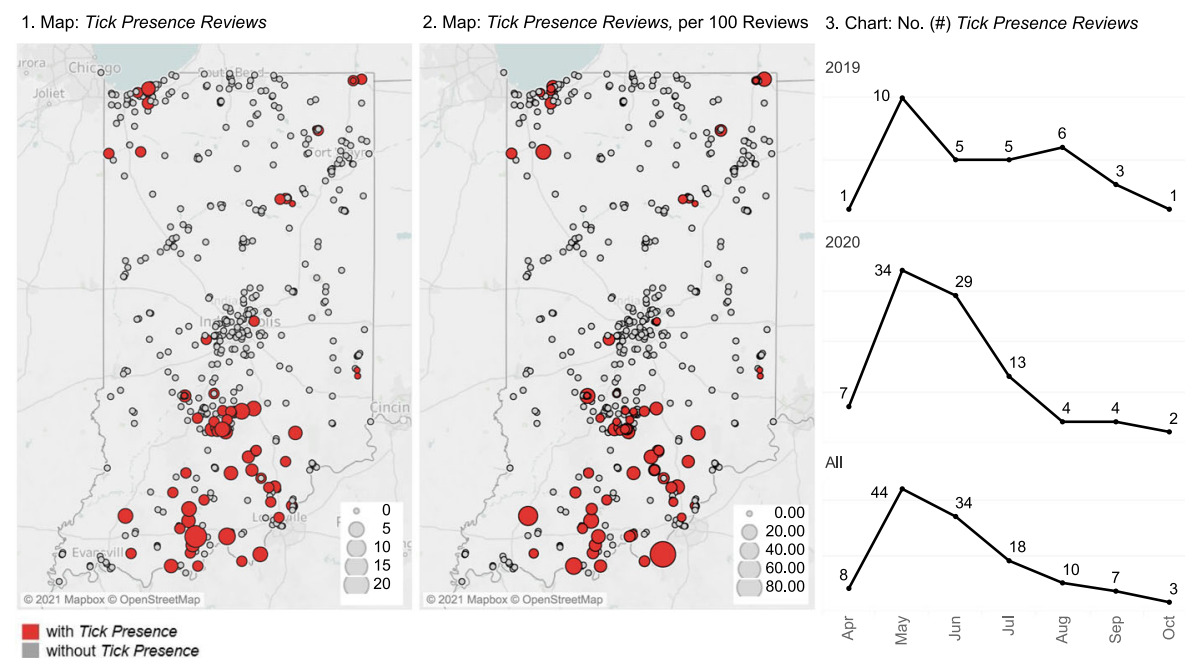

Fig. 1 Tick Encounter Patterns, Tick Presence Reviews = 124, all Indiana trails $N=697$

notably, of these, 11 had noted Tick Presence while on the trail and 4 had noted Tick Absence. Fewer users reported other protective behaviors, including wearing Protective Clothing that they perceived would aide in preventing a tick bite-e.g., wearing pants and long socks or wearing light color clothing $(n=5 / 147,3.40 \%)$. Only two had indicated that they took a Shower PostRecreation and used that activity to search for tick bites.

A larger proportion of tick-related reviews included a tick protective behavior Recommendation, wherein they suggest to fellow website users that they practice a protective behavior at this trail $(n=37 / 147,25.17 \%)$.

\section{Recreational deterrence}

Another recurrent theme was that of Recreational Deterrence. This portion of tick-related reviews (11/147, $7.48 \%$ ) included some reference to current or future deterrence from recreation at the specific trail of the review. More than half of these reviews [6] indicated that the ticks deterred recreation in the moment, e.g. the user turned around or shortened their hike due to the tick(s) encountered. The others [5] indicating that they would avoid the trail in the future, often in the context of avoiding that location during a particular season or month.

\section{Discussion}

A persistent challenge associated with reducing tickborne illnesses is the difficulty in determining the location of actual human-tick encounters [27]. A strength of the present study is that it provides evidence of such encounters, while many other surveillance methods, such as drag sampling or $\mathrm{CO}_{2}$-baited tick traps, do not. [28] By analyzing data obtained from online, user-generated trail reviews, we (a) pinpointed specific trails of reported
Tick Presence, (b) determined spatial and temporal patterns of Tick Presence, (c) identified the trail characteristics that are significantly associated with Tick Presence Reviews, and (d) explored the role of tick encounter in trail users' adaptive behaviors or recreational deterrence.

Our results indicated that online user reviews showed Tick Presence in all three regions of the state, although Tick Presence occurred significantly more frequently in the Hoosier state's southern region, an area characterized by dense plots of forested, public lands, particularly the Hoosier National Forest, in contrast to central and northern portions of the state [29]. This finding supports other research which has identified an association between the state's southern region and increased tick presence, particularly by specific species (Amblyomma americanum) and settings (peri-domestic) [30, 31], as well as tick-borne disease diagnoses [32]. Given this body of evidence, systematic active surveillance of tick populations, as well as coordinated public health efforts regarding tick borne disease awareness and prevention, might well be targeted to recreational trails in this region. Online user reviews also indicate a peak in Tick Presence in May, and a tapering in reported Tick Presence through the subsequent summer and fall months. This observed pattern is generally in agreement with active tick surveillance and recreational trail use patterns in Indiana, which have indicated that tick activity and recreational trail use are highest during late spring to early summer [24, 33]; consequently, communication efforts to inform trail users of increased, seasonal late Spring risks may be warranted.

Additionally, results revealed that federal Land Management and a trail's Elevation Gain both were significantly associated with the number of Tick Presence Reviews. Given that others have indicated that sub-state 


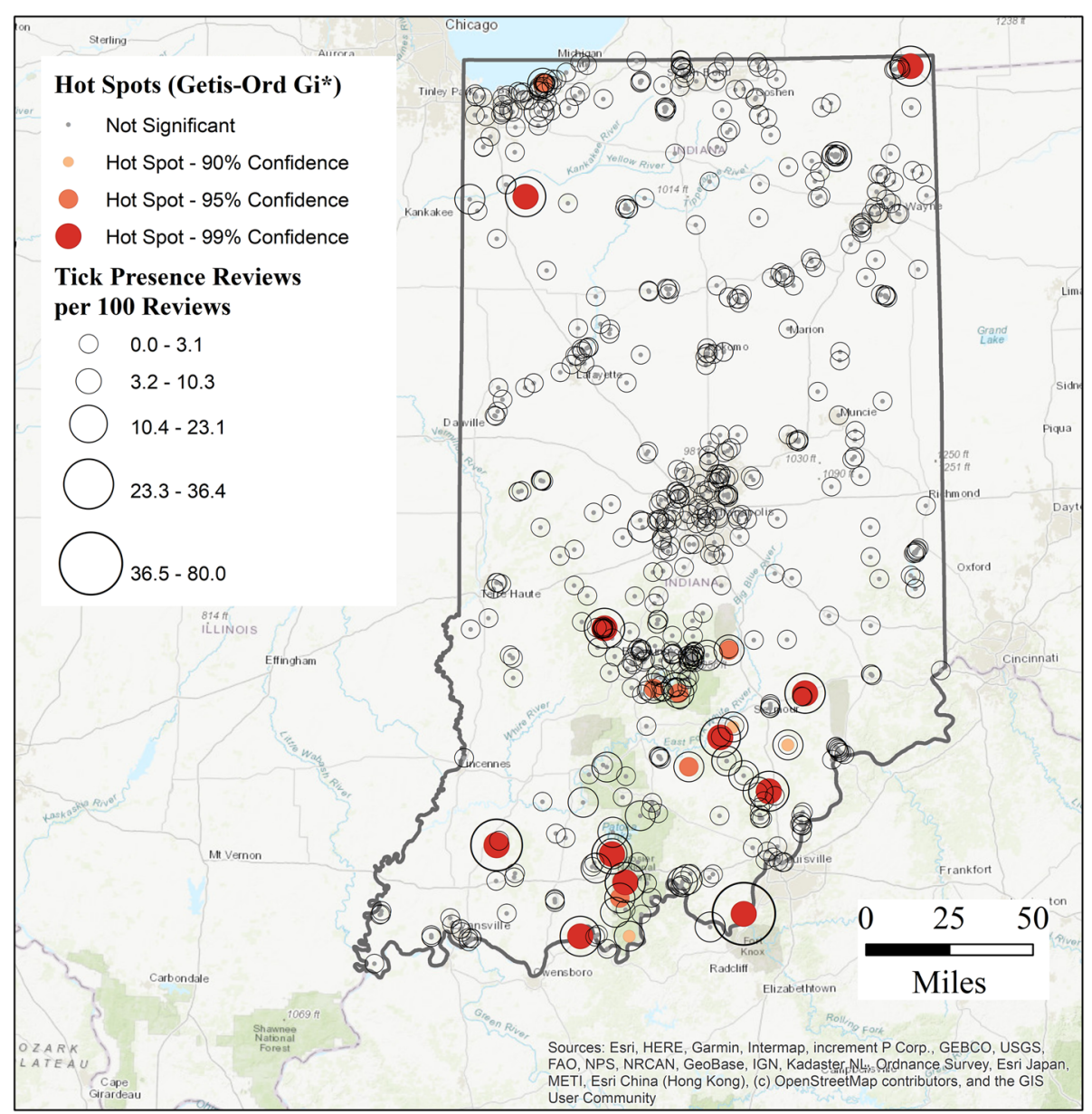

Fig. 2 Hot spot Analysis of Tick presence Reviews per 100, all Indiana trails $N=697$

level (municipal, county) governmental entities may need increased support for tick and pathogen surveillance [14], the association with Tick Presence Reviews identified here instead reinforces the crucial role of federal land management agencies in tick surveillance and control practices. However, the association between private land management-frequently under the control of a local land trust-and Tick Presence Reviews warrants further investigation. While not "public" they are generally "publicly accessible" and may represent an opportunity in tick surveillance efforts and research, as land trusts can aide in mitigating environmental problems [34]. The significant association between Elevation Gain and Tick Presence Reviews is also notable; we perceive that this trail characteristic may serve as a surrogate for the trail's terrain and ruggedness. As such, Elevation Gain may serve as a proxy indicator of users' travel to higher-risk, undeveloped and more remote habitats, increasing the odds of tick encounter [8]; this finding warrants increased efforts to recommend PPB adoption among users who recreate on more arduous trails.
Qualitative data reflecting the adoption and recommendation of protective behaviors, as well as Recreational Deterrence, illuminated important context to the tick-related user experience. Repellent Application was the most frequently reported tick protective behavior, a finding that is aligned with extant literature which often places this behavior amongst the top tick protective behaviors generally $[35,36]$ and in Indiana, specifically $[37$, 38]. Other behaviors (Protective Clothing, Shower PostRecreation) were mentioned in fewer than $5 \%$ of tickrelated user reviews. Recreational Deterrence was also mentioned in a subset of reviews, indicating the degree to which a tick(s) encounter can negatively impact current and future outdoor recreation experiences. However, given the open-ended nature of a user review, it is feasible that users practiced a tick protective behavior or were deterred but omitted those details, especially with respect to an activity that occurs post-exposure, usually in the privacy of one's own home (e.g. Shower PostRecreation). To that end, one key purpose of an online user review is often to share important information with 
Table 3 Description of Indiana Trails by Trail Characteristics and Tick Presence $(N=697)$

\begin{tabular}{|c|c|c|c|c|c|c|c|}
\hline & \multicolumn{2}{|c|}{$\begin{array}{l}\text { Trails } \\
\text { indicating } \\
\text { Tick Presence }\end{array}$} & \multicolumn{2}{|c|}{$\begin{array}{l}\text { Trails not indicating } \\
\text { Tick Presence }\end{array}$} & \multicolumn{2}{|c|}{ Overall } & \multirow[t]{2}{*}{$p$-value } \\
\hline & $\bar{n}$ & $\%$ & $\mathrm{n}$ & $\%$ & $\mathrm{n}$ & $\%$ & \\
\hline Count & 65 & - & 632 & - & 697 & $100 \%$ & - \\
\hline \multicolumn{8}{|l|}{ State Region } \\
\hline North & 12 & $18 \%$ & 222 & $35 \%$ & 234 & $34 \%$ & \multirow[t]{3}{*}{$<0.001^{* * *}$} \\
\hline Central & 3 & $5 \%$ & 212 & $34 \%$ & 215 & $31 \%$ & \\
\hline South & 50 & $77 \%$ & 198 & $31 \%$ & 248 & $36 \%$ & \\
\hline \multicolumn{8}{|l|}{ Land Management Type } \\
\hline Municipal & 3 & $5 \%$ & 133 & $21 \%$ & 136 & $20 \%$ & \multirow[t]{6}{*}{$<0.001^{* * *}$} \\
\hline County & 1 & $2 \%$ & 78 & $12 \%$ & 79 & $11 \%$ & \\
\hline State & 31 & $48 \%$ & 220 & $35 \%$ & 251 & $36 \%$ & \\
\hline Federal & 22 & $34 \%$ & 48 & $8 \%$ & 70 & $10 \%$ & \\
\hline Private & 6 & $9 \%$ & 101 & $16 \%$ & 107 & $15 \%$ & \\
\hline Unknown & 2 & $3 \%$ & 52 & $8 \%$ & 54 & $8 \%$ & \\
\hline \multicolumn{8}{|l|}{ Route Type } \\
\hline Loop & 53 & $82 \%$ & 463 & $73 \%$ & 516 & $74 \%$ & \multirow[t]{3}{*}{0.348} \\
\hline Out \& back & 9 & $14 \%$ & 129 & $20 \%$ & 138 & $20 \%$ & \\
\hline Point to point & 3 & $5 \%$ & 40 & $6 \%$ & 43 & $6 \%$ & \\
\hline Average Trail Length, mi & 6.2 & - & 4.2 & - & 4.4 & - & $<0.001^{* * *}$ \\
\hline (Median, mi) & 4.4 & & 2.2 & & 2.4 & & \\
\hline Average Elevation Gain, $\mathrm{ft}$ & 721.3 & - & 278.9 & - & 319.9 & - & $<0.001^{* * *}$ \\
\hline (Median, ft) & 472 & & 111 & & 124 & & \\
\hline
\end{tabular}

Last column reflects results of Chi-square tests of independence for State Region, Land Management Type, and Route Type variables. Last column reflects results of Mann-Whitney $\mathrm{U}$ nonparametric tests of differences for Average trail length (mi) and Average elevation gain (ft) variables $p<0.05 ;{ }^{* *} p<0.01,{ }^{* * *} p<0.001$

other, future users; this may explain why, of the themes evaluated, behavioral Recommendation, wherein a user recommends that other users practice a protective behavior(s), appeared most frequently.

One limitation to the generalizability of this study's findings is that tick abundance can vary dramatically along difference sections of an individual trail, given changes in ecological conditions (e.g. areas untreated by a controlled burn) and land use characteristics (e.g. pasture land) [12, 13]; this level of data granularity was not captured in our data. Additionally, the methods applied likely underreport Tick Presence by users on online trail review social media websites, particularly because AllTrail.com users were not aware that their review(s) would be analyzed for this content; as a result, it is possible that users encountered ticks but made no such indication in their online review. Additionally, there would be users who encountered ticks but were not AllTrail. com users or those who do use AllTrails.com, but do not leave trail reviews. It is also possible that a recreational trail user may have acquired a tick elsewhere, incorrectly assuming the exposure occurred at the trail reviewed. Still, we believe our methods reflect minimal recall bias, instead providing generally unbiased testament of recreational trail users' tick encounters.

\section{Conclusions}

We believe this research represents a low-cost and promising tool for identifying specific recreational trails that warrant more robust active surveillance, particularly at locations that may be under-surveilled, like municipal and county locations [14] as well as those managed by private institutions, such as local land trusts. Furthermore, despite the online and voluntary nature of data collected, identification of ticks at nearly $10 \%$ of trails can be contextualized within comparable research; in a study examining presence of Ixodes scapulari along more than $900 \mathrm{~km}$ of the Appalachian trail from West Virginia to Vermont, ticks presence was indicated at 21 (4.3\%) of actively surveilled sites $(N=489)$ [39]. Finally, research of this kind may also be particularly useful given its ability to summarize or improve peer-to-peer communication; individuals who are fearful of ticks and seek to avoid areas of documented tick encounters, such 
Table 4 Negative Binomial Regression of Tick Presence Reviews $(N=697)$

\begin{tabular}{|c|c|c|c|}
\hline & \multicolumn{3}{|c|}{ Response Variable: } \\
\hline & \multicolumn{3}{|c|}{ Tick Presence Reviews } \\
\hline & Estimate & Std. Error & $p$ \\
\hline \multicolumn{4}{|l|}{ State Region } \\
\hline North (Reference) & 0.000 & & \\
\hline Central & -0.923 & 0.618 & 0.135 \\
\hline South & 1.295 & 0.379 & $0.001^{* * *}$ \\
\hline \multicolumn{4}{|l|}{ Land Management Type } \\
\hline Municipal (Reference) & 0.000 & & \\
\hline County & -0.751 & 1.219 & 0.538 \\
\hline State & 1.231 & 0.680 & 0.070 \\
\hline Federal & 2.415 & 0.710 & $0.001^{* * *}$ \\
\hline Private & 1.431 & 0.721 & $0.047^{*}$ \\
\hline Other & 1.170 & 0.875 & 0.181 \\
\hline \multicolumn{4}{|l|}{ Route Type } \\
\hline Loop (Reference) & 0.000 & & \\
\hline Out \& back & -0.127 & 0.401 & 0.751 \\
\hline Point to point & -1.232 & 0.878 & 0.161 \\
\hline Trail Length (in mi) & -0.095 & 0.071 & 0.180 \\
\hline Elevation Gain(in feet) & 0.001 & 0.001 & $0.050^{*}$ \\
\hline
\end{tabular}

as those peoples who experience chronic symptoms following Lyme Disease, may use the data captured here to avoid specific trails [40]. Our results also indicate that trail review websites may want to broaden the categories of variables collected and reported; for instance, a binary yes/no indicator of Tick Presence may inform future recreational trail/website users.

Tick-borne diseases represent the most common vector-borne diseases reported nationwide and have more than doubled over the past two decades [41]. Still, with this study we do not seek to discourage outdoor recreation, with its many associated positive health outcomes [42, 43], but instead seek to identify recreational trail sites of known tick encounters as one part of the process in preventing vector-borne disease [44]. Given the difficulty in controlling and preventing vector-borne diseases, we believe that analysis of online, usergenerated reviews represents an innovative method in identifying the patterns of activities and behaviors that increase tick exposure. Going forward, future research might seek to (a) validate tick populations identified here through active surveillance or (b) evaluate the transferability of our methods to other regions, e.g. parts of New England, where many tick-borne diseases are endemic, or the Mountain West, where land is predominantly publicly owned.

\section{Supplementary Information}

The online version contains supplementary material available at https://doi. org/10.1186/s12889-021-10940-4.

\section{Additional file 1.}

\section{Acknowledgements}

Not applicable.

\section{Authors' contributions}

Author K.R.A. led the conception and design of the study, performed data collection, contributed to statistical analysis, and wrote the manuscript. Author J.B. aided with statistical and spatial analysis, drafted text for methods and results, and provided manuscript revisions. Author O.O. participated in the design of the study and provided manuscript revisions. The author(s) read and approved the final manuscript.

Funding

Not applicable.

\section{Availability of data and materials}

The dataset reflecting Tick Presence Review on a per-trail basis are included in this article's supplementary information files. The underlying data reflecting verbatim user review comments are not available due the identifiable nature of this qualitative data, as their content can be matched to individual user accounts publicly accessible online.

\section{Declarations}

Ethics approval/consent to participate

Studies that utilize publicly available online data and that do not gather identifiable information do not require IRB approval.

\section{Consent for publication}

N/A

\section{Competing interests}

On behalf of all authors, the corresponding author attests that there are no conflicts of interests.

\section{Author details}

${ }^{1}$ Department of Health \& Wellness Design, School of Public Health, Indiana University Bloomington, 1025 E. 7th Street, IN 47405 Bloomington, USA. 2Department of Geography, College of Arts \& Sciences, Indiana University Bloomington, 701 E. Kirkwood Avenue, Bloomington, IN 47405, USA.

Received: 3 February 2021 Accepted: 22 April 2021

Published online: 13 May 2021

\section{References}

1. U.S. Centers for Disease Control and Prevention. Record Number of Tickborne Diseases Reported in U.S. in 20172018 [Available from: https:// www.cdc.gov/media/releases/2018/s1114-record-number-tickborne-diseases. html.

2. U.S. Centers for Disease Control and Prevention. Tickborne Disease Surveillance Data Summary 2019 [Available from: https://www.cdc.gov/ticks/ data-summary/index.html.

3. Sonenshine DE. Range expansion of tick disease vectors in North America: implications for spread of tick-borne disease. Int J Environ Res Public Health. 2018;15(3):478. https://doi.org/10.3390/ijerph15030478.

4. CDC. Geographic Distribution. Atlanta, Georgia: Centers for Disease Control and Prevention; 2018.

5. Adjemian J, Weber IB, McQuiston J, Griffith KS, Mead PS, Nicholson W, et al. Zoonotic infections among employees from Great Smoky Mountains and Rocky Mountain national parks, 2008-2009. Vector-Borne and Zoonotic Diseases. 2012;12(11):922-31. https://doi.org/10.1089/vbz.2011.0917.

6. Mitcham JR, Talley JL, Noden BH. Risk of encountering questing ticks (Ixodidae) and the prevalence of tickborne pathogens in Oklahoma state parks. Southwestern Entomologist. 2018:43(2):303-15. https://doi.org/10.3 958/059.043.0202 
7. Johnson TL, Graham CB, Boegler KA, Cherry CC, Maes SE, Pilgard MA, et al. Prevalence and diversity of tick-borne pathogens in nymphal Ixodes scapularis (Acari: Ixodidae) in eastern national parks. J Med Entomol. 2017; 54(3):742-51. https://doi.org/10.1093/jme/tjw213.

8. Falco RC, Fish D. Potential for exposure to tick bites in recreational parks in a Lyme disease endemic area. Am J Public Health. 1989;79(1):12-5. https:// doi.org/10.2105/AJPH.79.1.12.

9. Fleer KA, Foley P, Calder L, Foley JE. Arthropod vectors and vector-borne bacterial pathogens in Yosemite National Park. J Med Entomol. 2014;48(1): $101-10$.

10. Mead P, Hook S, Niesobecki S, Ray J, Meek J, Delorey M, et al. Risk factors for tick exposure in suburban settings in the northeastern United States. Ticks and Tick-borne Dis. 2018;9(2):319-24. https://doi.org/10.1016/j.ttbdis.2 017.11.006.

11. Salkeld DJ, Porter WT, Loh SM, Nieto NC. Time of year and outdoor recreation affect human exposure to ticks in California. United States Ticks and Tick-Borne Dis. 2019;10(5):1113-7. https://doi.org/10.1016/j.ttbdis.2019. 06.004.

12. Cilek J, Olson M. Seasonal distribution and abundance of ticks (Acari: Ixodidae) in northwestern Florida. J Med Entomol. 2000;37(3):439-44. https://doi.org/10.1093/jmedent/37.3.439.

13. Richter D, Matuschka F-R. Differential risk for Lyme disease along hiking trail. Germany Emerging Infectious Diseases. 2011;17(9):1704-6. https://doi.org/1 0.3201/eid1709.101523.

14. Mader EM, Ganser C, Geiger A, Harrington LC, Foley J, Smith RL, et al. A survey of tick surveillance and control practices in the United States. J Med Entomol. 2020.

15. Omodior O, Pennington-Gray L, Donohoe H. Efficacy of the theory of planned behavior in predicting the intention to engage in tick-borne disease personal protective behavior amongst visitors to an outdoor recreation center. J Park Recreation Administration. 2015;33:2.

16. Shadick NA, Daltroy LH, Phillips CB, Liang US, Liang MH. Determinants of tick-avoidance behaviors in an endemic area for Lyme disease. Am J Prev Med. 1997;13(4):265-70. https://doi.org/10.1016/S0749-3797(18)30173-9.

17. Aenishaenslin C, Bouchard C, Koffi JK, Ogden NH. Exposure and preventive behaviours toward ticks and Lyme disease in Canada: results from a first national survey. Ticks and Tick-Borne Dis. 2017;1:112-8.

18. Gould LH, Nelson RS, Griffith KS, Hayes EB, Piesman J, Mead PS, et al. Knowledge, attitudes, and behaviors regarding Lyme disease prevention among Connecticut residents, 1999-2004. Vector-Borne and Zoonotic Dis. 2008;8(6):769-76. https://doi.org/10.1089/vbz.2007.0221.

19. Eisen $L$, Wong $D$, Shelus $V$, Eisen RJ. What is the risk for exposure to vectorborne pathogens in United States national parks? J Med Entomol. 2013; 50(2):221-30. https://doi.org/10.1603/ME12228.

20. Eisen L, Eisen RJ. Need for improved methods to collect and present spatial epidemiologic data for vectorborne diseases. Emerg Infect Dis. 2007;13(12): 1816-20. https://doi.org/10.3201/eid1312.070211.

21. Johnson B, Scott-Sheldon L, Carey M. Meta-synthesis of health behavior change meta-analyses. Am J Public Health. 2010;100(11):2193-8. https://doi. org/10.2105/AJPH.2008.155200.

22. AllTrails.com. 2020 [Available from: https://www.alltrails.com/.

23. County Surveyors Association of Indiana. Directory of County Surveyors n.d. [Available from: https://www.indianacountysurveyors.org/directory.html.

24. Rynkiewicz EC, Clay K. Tick community composition in Midwestern US habitats in relation to sampling method and environmental conditions. Exp Appl Acarol. 2014;64(1):109-19. https://doi.org/10.1007/s10493-014-9798-7.

25. Eppley Institute. 2017 Indiana trails study. Bloomington, IN: Eppley Institute for Parks and Public Lands; 2018.

26. Liu B, Pennington-Gray L, Donohoe H, Omodior O. New York city bed bug crisis as framed by tourists on TripAdvisor. Tour Anal. 2015;20(2):243-50. https://doi.org/10.3727/108354215X14265319207597.

27. Ginsberg HS. Vector-borne Diseases on Fire Island, New York (Fire Island National Seashore Science Synthesis Paper). Boston: National Park Service; 2005. Report No.: NPS/NER/NRTR-2005/018

28. Eisen RJ. Paddock CD. Journal of Medical Entomology: Tick and tickborne pathogen surveillance as a public health tool in the United States; 2020.

29. Martinuzzi S, Stewart SI, Helmers DP, Mockrin MH, Hammer RB, Radeloff VC. The 2010 wildland-urban interface of the conterminous United States. Newtown Square, PA: U.S. Forest Service; 2015.

30. Omodior O, Eze P, Anderson KR, et al. Ticks \& Tick-borne Dis. 2021;12(3): 101684. https://doi.org/10.1016/j.ttbdis.2021.101684.
31. Indiana Department of Health. Amblyomma americanum 2020 [Available from: https://www.in.gov/isdh/28009.htm.

32. Omodior O, Kianersi S, Luetke M. Spatial clusters and non-spatial predictors of tick-borne disease diagnosis in Indiana. Journal of Community Health. 2019.

33. Indiana Department of Natural Resources. Indiana trail count analysis 2020 [Available from: https://www.in.gov/dnr/outdoor/10484.htm.

34. Grant L, Langpap C. Private provision of public goods by environmental groups. Proc Natl Acad Sci. 2019;116(12):5334-40. https://doi.org/10.1073/ pnas.1805336115.

35. Bron GM, Fernandez MdP, Larson SR, Maus A, Gustafson D, Tsao II, et al. Context matters: contrasting behavioral and residential risk factors for Lyme disease between high-incidence states in the Northeastern and Midwestern United States. Ticks \& Tick-borne Dis. 2020;11(6):101515.

36. Bayles BR, Evans G, Allan BF. Knowledge and prevention of tick-borne diseases vary across an urban-to-rural human land-use gradient. Ticks and tick-borne Dis. 2013;4(4):352-8. https://doi.org/10.1016/j.ttbdis.2013.01.001.

37. Omodior O, Anderson KR, Clark W, Eze P, Donohoe H. Preventing tick-bites among children in Indiana, USA: an analysis of factors associated with parental protective behaviors. Ticks and Tick-borne Dis. 2021;12(2):101647. https://doi.org/10.1016/j.ttbdis.2020.101647.

38. Omodior O, Luetke M, Kianersi S, Colón A. Predictors of tick exposure riskreduction behavior in Indiana. J Community Health. 2020:1-9.

39. Oliver J, Howard JJ. Occurrence of Ixodes scapularis (Acari: Ixodidae) on a selected segment of the Appalachian Trail. J Med Entomol. 1998;35(1):54-8. https://doi.org/10.1093/jmedent/35.1.54.

40. Rebman AW, Aucott JN, Weinstein ER, Bechtold KT, Smith KC, Leonard L. Living in limbo: contested narratives of patients with chronic symptoms following Lyme disease. Qual Health Res. 2017;27(4):534-46. https://doi. org/10.1177/1049732315619380.

41. Rosenberg R, Lindsey NP, Fischer M, Gregory CJ, Hinckley AF, Mead PS, et al. Vital signs: trends in reported vectorborne disease cases-United States and territories, 2004-2016. Morb Mortal Wkly Rep. 2018;67(17):496-501. https:// doi.org/10.15585/mmwr.mm6717e1.

42. Frumkin H, Bratman GN, Breslow SJ, Cochran B, Kahn PH Jr, Lawler JJ, et al. Nature contact and human health: a research agenda. Environ Health Perspect. 2017;125(7):075001. https://doi.org/10.1289/EHP1663.

43. Shanahan DF, Bush R, Gaston KJ, Lin BB, Dean J, Barber E, et al. Health benefits from nature experiences depend on dose. Sci Rep. 2016;6(1):28551. https://doi.org/10.1038/srep28551.

44. Quine CP, Barnett J, Dobson AD, Marcu A, Marzano M, Moseley D, et al. Frameworks for risk communication and disease management: the case of Lyme disease and countryside users. Philosophical Transactions of the Royal Society B: Biological Sci. 2011;366(1573):2010-22. https://doi.org/10.1098/ rstb.2010.0397.

\section{Publisher's Note}

Springer Nature remains neutral with regard to jurisdictional claims in published maps and institutional affiliations.
Ready to submit your research? Choose BMC and benefit from:
- fast, convenient online submission
- thorough peer review by experienced researchers in your field
- rapid publication on acceptance
- support for research data, including large and complex data types
- gold Open Access which fosters wider collaboration and increased citations
- maximum visibility for your research: over $100 \mathrm{M}$ website views per year
At BMC, research is always in progress. 